\title{
Kinetics and mechanism of polymerization of methyl methacrylate initiated by stibonium ylide
}

\author{
A K SRIVASTAVA and AJEY KUMAR CHAURASIA \\ Department of Chemistry, H B Technological Institute, Kanpur 208 002, India \\ e-mail: akspolym@rediffmail.com
}

MS received 6 September 2002; revised 25 July 2003

\begin{abstract}
Homopolymerization of methyl methacrylate (MMA) was carried out in the presence of triphenylstibonium 1,2,3,4-tetraphenyl-cyclopentadienylide as an initiator in dioxane at $65^{\circ} \mathrm{C} \pm 0 \cdot 1{ }^{\circ} \mathrm{C}$. The system follows non-ideal radical kinetics $\left(R_{p} \propto[M]^{1 \cdot 4}[I]^{0 \cdot 44}\right)$ due to primary radical termination as well as degradative chain-transfer reaction. The overall activation energy and average value of $k_{p}^{2} / k_{t}$ were $64 \mathrm{~kJ} \mathrm{~mol}^{-1}$ and $0.173 \times 10^{-3} 1 \mathrm{~mol}^{-1} \mathrm{~s}^{-1}$ respectively.
\end{abstract}

Keywords. Triphenylstiboniumylide; methyl methacrylate; non-ideal radical kinetics; mechanism.

\section{Introduction}

The stereospecific polymerization of various acrylates and methacrylate has been studied by using a variety of initiators such as triphenyl phosphine and iron(III) complex, ${ }^{1}$ thiol, ${ }^{2}$ the D-glucose-ceric ion redox system, ${ }^{3}$ benzyol peroxide, ${ }^{4}$ tert-hexyl peroxy pivalate $^{5}$ and fullerene. ${ }^{6}$ Recently, some ylides containing non-metals like nitrogen, ${ }^{7-10}$ sulphur ${ }^{11}$ and phosphorus $^{12}$ have been used for the polymerization of methyl methacrylate MMA.

Recently use of $p$-acetylenzylidene triphenyl arsonium ylide [ $p$-ABTAY] as radical initiator for the homopolymerization of methyl methacrylate, ${ }^{13}$ vinyl acetate $^{14}$ and copolymerization of styrene with vinyl acetate $^{15}$ has been reported.

The properties of ylides are very much dependent on the identity of the heteroatom. The dipolar and nucleophilic character of the ylides appear to increase their stability. However, the triphenylstibonium 1,2,3,4-tetraphenylcyclopentadienylide, because of its synthetic problems, has not been examined earlier in the polymer science.

\section{Experimental}

Monomer and solvents were purified according to procedures reported in literature. ${ }^{16,17}$ The ylide was prepared by the method of Lloyd. ${ }^{18}$ Briefly it is as follows.

*For correspondence
A solution of $2.19 \times 10^{-4}$ moles of 1,2,3,4-tetraphenylcyclopentadiene (Aldrich), $7.46 \times 10^{-4}$ moles of $p$-toluene sulphonylhydrazide (Fluka AG) in $6.3 \mathrm{ml}$ diethyl amine was kept at $0^{\circ} \mathrm{C}$ for 10 days. It was then followed by addition of $3.5 \mathrm{ml}$ water, $5 \mathrm{ml}$ ether and dried over anhydrous silica gel, when yellow crystals of diazo compound were obtained. It was washed with methanol.

A solution containing $2.64 \times 10^{-4}$ moles of diazocompound, $7.35 \times 10^{-5}$ moles of $\mathrm{Cu}$ (II) bishexafluoroacetylacetonato (Merck) as catalyst and $4.95 \times$ $10^{-5}$ moles of triphenylstibonium (Merck) in $10 \mathrm{ml}$ benzene were refluxed for $2 \mathrm{~h}$. The evaporation of the solvent in vacuum produced stibonium ylide in $14.5 \%$ yield.

\section{Polymerization procedure}

The polymerization was carried out in a dioxane at $65 \pm 0 \cdot 1^{\circ} \mathrm{C}$ under an inert atmosphere of nitrogen for $5 \mathrm{~h}$. The rate of polymerization $\left(R_{p}\right)$ was determined dilatometry from the slope of linear portion of conversion vs time plots. The intrinsic viscosity [ $\eta]$ of polymer(s) was determined in benzene at $30 \pm$ $0 \cdot 1{ }^{\circ} \mathrm{C}$ using an ubbelohde viscometer. The average degree of polymerization $\left(\bar{P}_{n}\right)$ was calculated. ${ }^{19}$

\section{Results and discussion}

The ylide initiated polymerization at $65^{\circ} \mathrm{C}$ have been summarized in (tables 1-3) and (figures 1-8) 
because it failed to initiate the polymerization below $60^{\circ} \mathrm{C}$.

\subsection{Effect of [ylide]}

The effect of stibonium ylide on the rate of polymerization was studied by varying the [ylide] from $1.16 \times 10^{-5}$ to $5.78 \times 10^{-5} \mathrm{~mol} \mathrm{l}^{-1}$, while keeping [MMA] constant as $3.0 \mathrm{~mol}^{-1}$ (figure 1 and table 1). The polymerization was associated with an induction period of about 50-60 min. The extended induction period is often seen feature in the case of ylide initiated polymerization of various vinyl monomers. ${ }^{20}$ The ylide initiated the radical polymerization of methyl methacrylate and the $R_{p}$ increased when ylide concentration increased from $1.16 \times 10^{-5}$ to $5.78 \times 10^{-5} \mathrm{~mol} \mathrm{l}^{-1}$. The value is less than expected for ideal radical kinetics. The initiator exponent, calculated from the slope of the plot $\log R_{p}$ versus $\log$ [ylide], is $0.44 \pm 0.01$ (Figure 2). The average degree of polymerization $\left(\bar{P}_{n}\right)$ decreases with the increase in [ylide] (table 1). The value of $k_{p}^{2} / k_{t}$, determined from the slope of a plot (figure 3 ) of $\left(1 / \bar{P}_{n}\right)$ vs $R_{p} /[M]^{2}$, is $0.173 \times 10^{-3} 1 \mathrm{~mol}^{-1} \mathrm{~s}^{-1}$.

\subsection{Effect of [MMA]}

The effect of [MMA] on the $R_{p}$ has been studied by varying [MMA] from 0.75 to $3.0 \mathrm{~mol} \mathrm{l}^{-1}$, whereas [ylide] has been kept constant $2.31 \times 10^{-5} \mathrm{~mol} \mathrm{l}^{-1}$ (table 2). It is clear that the $R_{p}$ is a direct function of [MMA]. The monomer exponent, calculated from the slope of the linear plot of $\log R_{p}$ against $\log$ [MMA], is $1.4 \pm 0.02$ (figure 4). This confirms that the system follows non-ideal kinetics. The average degree of polymerization increases with increase of monomer concentration (table 2). ${ }^{21-22}$

Table 1. Effect of [ylide] on the polymerization of methyl methacrylate [MMA].

$[\mathrm{MMA}]=3 \cdot 0 \mathrm{~mol} \mathrm{l}^{-1} ; \quad$ temperature $=65 \pm 0 \cdot 1^{\circ} \mathrm{C} ; \quad$ solvent $=$ dioxane; time $=300 \mathrm{~min}$

\begin{tabular}{lcccc}
\hline $\begin{array}{l}\text { Run } \\
\text { No. }\end{array}$ & $\begin{array}{c}\text { [ylide] } \times 10^{5} \\
\left(\mathrm{~mol} \mathrm{l}^{-1}\right)\end{array}$ & $\begin{array}{c}\text { Percentage } \\
\text { conversion }\end{array}$ & $\begin{array}{c}R_{p} \times 10^{5} \\
\mathrm{~mol}^{-1} \mathrm{~s}^{-1}\end{array}$ & $\bar{P}_{n}$ \\
\hline 1 & 1.16 & 6.8 & 1.20 & 780 \\
2 & 2.31 & 7.9 & 1.40 & 736 \\
3 & 3.47 & 9.6 & 1.66 & 711 \\
4 & 4.62 & 10.7 & 1.94 & 672 \\
5 & 5.78 & 13.1 & 2.50 & 749 \\
\hline
\end{tabular}

\subsection{Effect of temperature}

The polymerization runs were also carried out at 70 and $75^{\circ} \mathrm{C}$ in order to evaluate energy of activation of the system. The value, calculated from the linear

Table 2. Effect of methyl methacrylate concentration on the polymerization of methyl methacrylate [MMA].

[Ylide $]=2.31 \times 10^{-5} \mathrm{~mol} \mathrm{l}^{-1} ; \quad$ temperature $=65 \pm 0.1^{\circ} \mathrm{C} ; \quad$ solvent $=$ dioxane; time $=300 \mathrm{~min}$

\begin{tabular}{lcccc}
\hline $\begin{array}{l}\text { Run } \\
\text { No. }\end{array}$ & $\begin{array}{c}{[\mathrm{MMA}] \times 10^{5}} \\
\left(\mathrm{~mol} \mathrm{l}^{-1}\right)\end{array}$ & $\begin{array}{c}\text { Percentage } \\
\text { conversion }\end{array}$ & $\begin{array}{c}R_{p} \times 10^{5} \\
\mathrm{~mol} \mathrm{l}^{-1} \mathrm{~s}^{-1}\end{array}$ & $\bar{P}_{n}$ \\
\hline 1 & 0.75 & 3.6 & 0.21 & 458 \\
2 & 1.50 & 4.6 & 0.50 & 521 \\
3 & 2.25 & 6.1 & 0.91 & 649 \\
4 & 3.00 & 7.9 & 1.40 & 736 \\
\hline
\end{tabular}

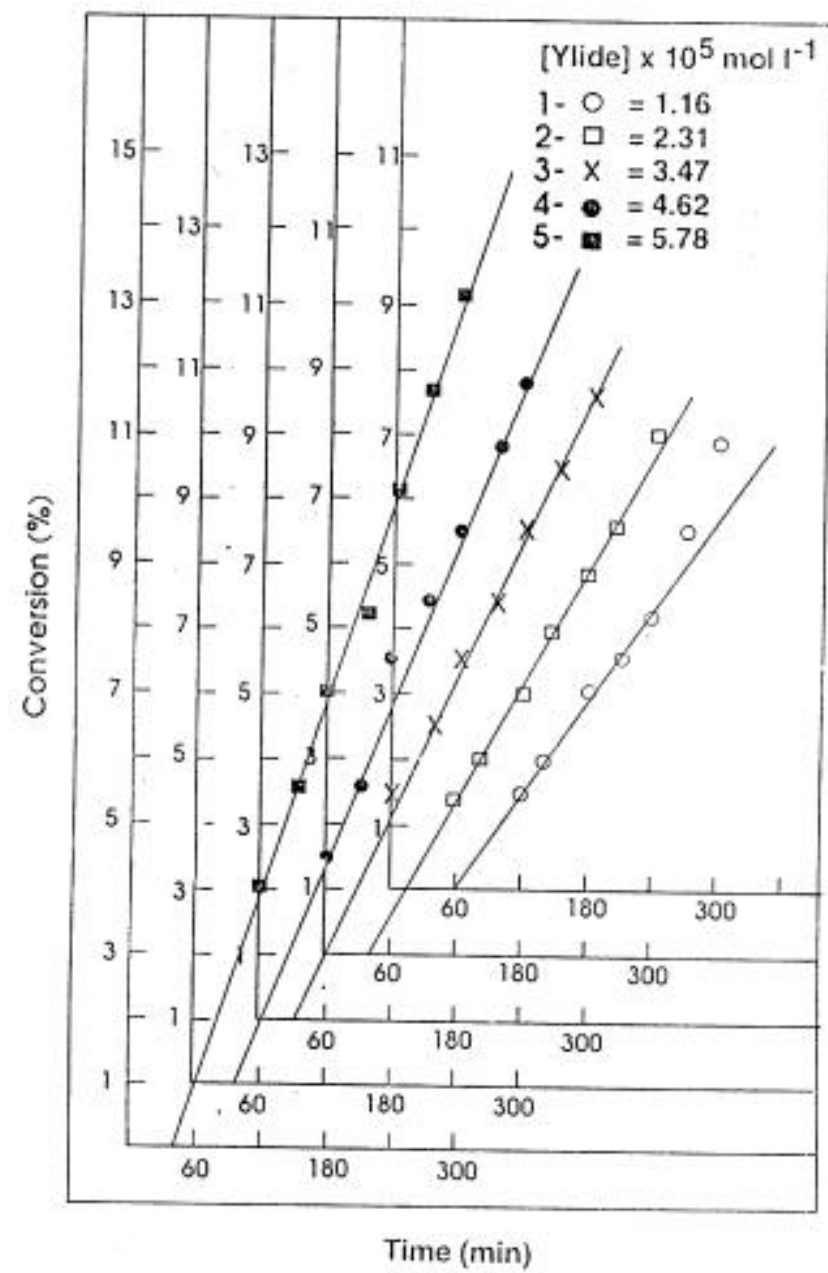

Figure 1. Percentage conversion vs time plots for homopolymerization of methyl methacrylate: [ylide] $=1.16$ to $5.78 \times 10^{-5} \mathrm{~mol} \mathrm{l}^{-1} ; \quad[\mathrm{MMA}]=3.0 \mathrm{~mol} \mathrm{l}^{-1} ; \quad$ temp. $=65 \pm$ $0.1{ }^{\circ} \mathrm{C} ; \quad$ solvent $=$ dioxene; $\quad$ time $=300 \mathrm{~min} ; \quad[(1)=1.16 \times$ $10^{-5} \mathrm{~mol} \mathrm{l}^{-1} ; \quad(2)=2.31 \times 10^{-5} \mathrm{~mol} \mathrm{l}^{-1} ; \quad$ (3) $=3.47 \times 10^{-5}$ $\mathrm{moll}^{-1}$; (4) $\left.=4.67 \times 10^{-5} \mathrm{~mol} \mathrm{l}^{-1} ;(5)=5.78 \times 10^{-5} \mathrm{~mol} \mathrm{l}^{-1}\right]$. 


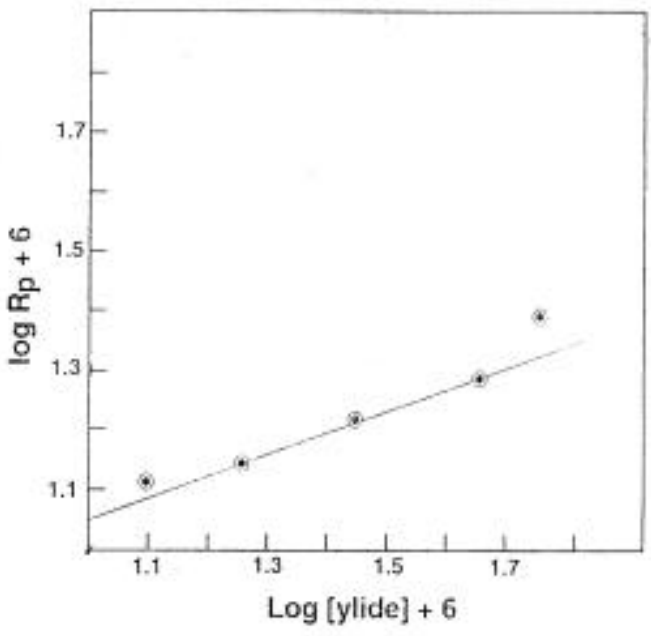

Figure 2. Relationship $\log R_{p}$ and $\log$ [ylide] for the homopolymerzation of methyl methacrylate: [ylide] = 1.16 to $5.78 \times 10^{-5} \mathrm{~mol} \mathrm{l}^{-1} ; \quad[\mathrm{MMA}]=3.0 \mathrm{~mol} \mathrm{l}^{-1}$; temp. $=$ $65 \pm 0 \cdot 1^{\circ} \mathrm{C}$; time $=300 \mathrm{~min}$; solvent $=$ dioxene.

Table 3. Effect of inhibitor on the rate of polymerization of [MMA]

[Ylide $=2.31 \times 10^{5} \mathrm{~mol} \mathrm{l}^{-1} ; \quad[\mathrm{MMA}]=3.0 \mathrm{~mol} \mathrm{l}^{-1} ; \quad$ temp. $=$ $65 \pm 0 \cdot 1^{\circ} \mathrm{C}$; time $=300 \mathrm{~min}$; solvent $=$ dioxene

\begin{tabular}{cccc}
\hline $\begin{array}{c}\text { Run } \\
\text { No. }\end{array}$ & $\begin{array}{c}\text { [Inhibitor } \\
\left(\mathrm{mol}^{-1}\right)\end{array}$ & $\begin{array}{c}\text { Percentaqge } \\
\text { conversion }\end{array}$ & $\begin{array}{c}R_{p} \times 10^{5} \\
\left(\mathrm{~mol} \mathrm{l}^{-1} \mathrm{~s}^{-1}\right)\end{array}$ \\
\hline 1 & - & 7.9 & 1.4 \\
2 & $\begin{array}{c}\text { Hydroquinone } \\
1.5 \times 10^{-3} \\
4.5 \times 10^{-3}\end{array}$ & 3.9 & 0.95 \\
& $7.5 \times 10^{-1}$ & No polymer & No polymer \\
& Nitrobenzene & & \\
3 & 0.81 & 4.4 & 1.0 \\
& 1.62 & 2.1 & 0.5 \\
4 & 2.43 & No polymer & No polymer \\
& Aniline & & \\
& 0.89 & 5.1 & 1.2 \\
& 1.78 & 3.8 & 1.1 \\
& 2.67 & No polymer & No polymer \\
\hline
\end{tabular}

plot of $\log R_{p}$ vs polymerization temperature, is $64 \mathrm{~kJ} \mathrm{~mol}^{-1}$ (figure 5).

\subsection{Causes of non-ideality}

The value of initiator exponent suggests that the system follows non-ideal kinetics. The kinetic nonideality can be explained by analyzing the role of triphenyl stibonium 1,2,3,4-tetraphenyl-cyclopendiene as primary radical termination and degradative chain transfer agent. To analyze the effect of primary

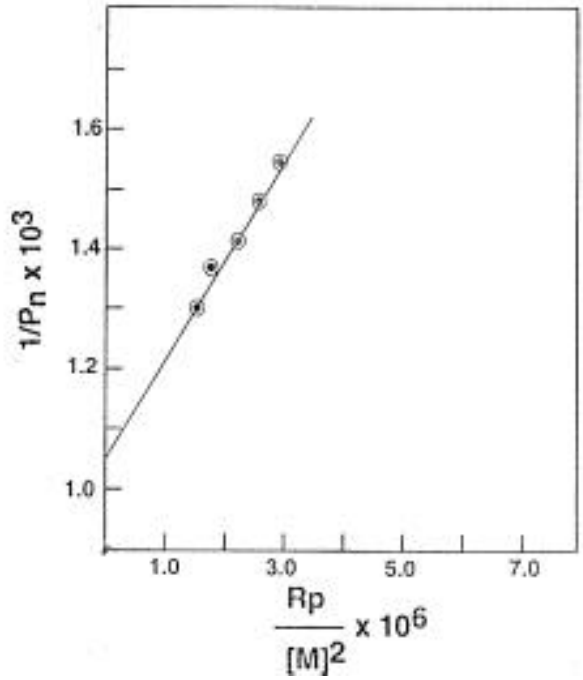

Figure 3. Relationship between $1 / \bar{P}_{n}$ and $R_{p} /[M]^{2}$ for the homopolymerzation of methyl methacrylate: [ylide] = 1.16 to $5.78 \times 10^{-5} \mathrm{~mol} \mathrm{l}^{-1}$; $[\mathrm{MMA}]=3.0 \mathrm{~mol} \mathrm{l}^{-1}$; temp. $=$ $65 \pm 0 \cdot 1^{\circ} \mathrm{C}$; time $=300 \mathrm{~min}$; solvent $=$ dioxene.

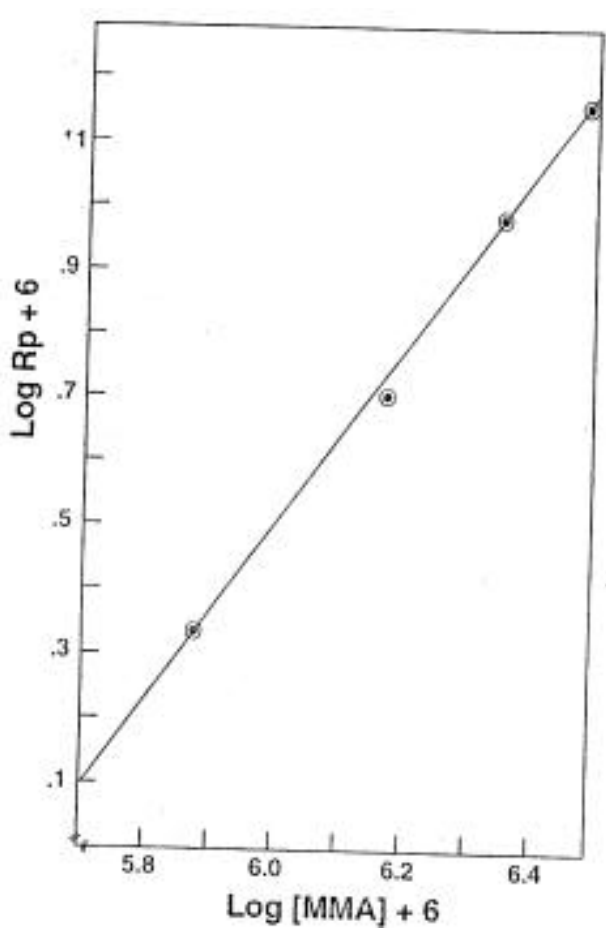

Figure 4. Relationship $\log [\mathrm{MMA}]$ and $\log R_{p}$ for the homopolymerzation of methyl methacrylate: [ylide] = $2.31 \times 10^{-5} \mathrm{~mol} \mathrm{l}^{-1} ; \quad[\mathrm{MMA}]=0.75$ to $3.0 \mathrm{~mol} \mathrm{l}^{-1}$; temp. $=$ $65 \pm 0 \cdot 1^{\circ} \mathrm{C}$; time $=300 \mathrm{~min}$; solvent $=$ dioxene.

radical termination a suitable modified expression given by Deb and Meherhoff ${ }^{23}$ in the following form is used: 


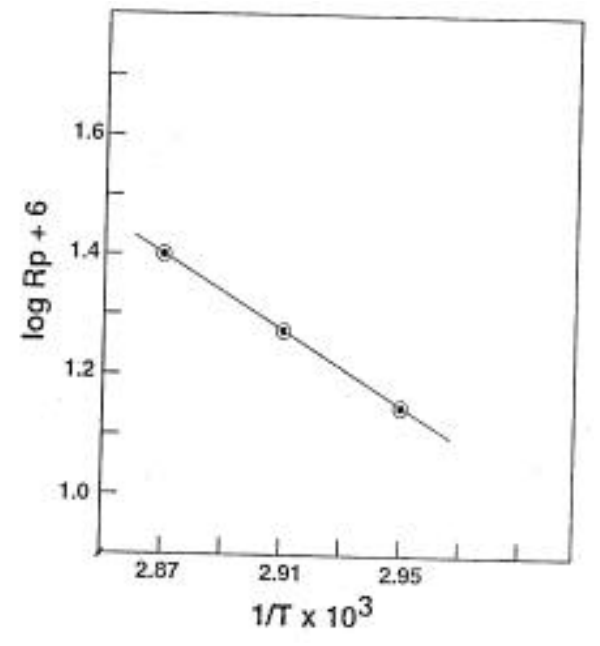

Figure 5. Plot of $\log R_{p}$ vs polymerization temperature (Arrhenius plot): $\quad\left[\right.$ ylide] $=2.31 \times 10^{-5} \mathrm{moll}^{-1}$; $[\mathrm{MMA}]=$ $3.0 \mathrm{~mol} \mathrm{l}^{-1} ; \quad$ temp. $=65, \quad 70, \quad 75 \pm 0.1^{\circ} \mathrm{C} ; \quad$ time $=300 \mathrm{~min}$; solvent $=$ dioxene .

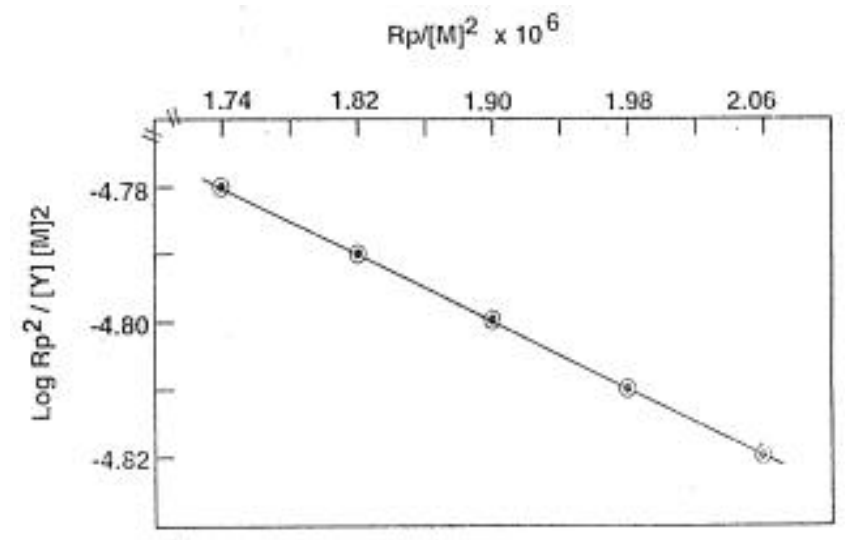

Figure 6. Plot of $\log R_{p}^{2} /[\mathrm{Y}][\mathrm{M}]^{2}$ and $R_{p} /[\mathrm{M}]^{2}$ : [ylide]= 1.16 to $5.78 \times 10^{-5} \mathrm{~mol} \mathrm{l}^{-1}$; $[\mathrm{MMA}]=2.53 \mathrm{~mol} \mathrm{l}^{-1}$; temp. $=$ $65 \pm 0 \cdot 1^{\circ} \mathrm{C}$; time $=300 \mathrm{~min}$; solvent $=$ dioxene.

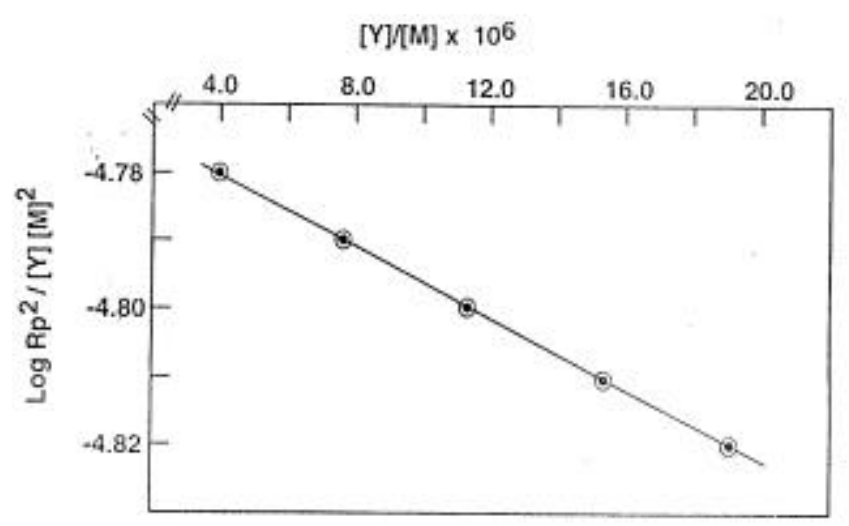

Figure 7. Plot of $\log R_{p}^{2} /[\mathrm{Y}][\mathrm{M}]^{2}$ and $[\mathrm{Y}] /[\mathrm{M}]$ : [ylide $]=$ 1.16 to $5.78 \times 10^{-5} \mathrm{~mol} \mathrm{l}^{-1}$; $[\mathrm{MMA}]=2.53 \mathrm{~mol} \mathrm{l}^{-1}$; temp. $=$ $65 \pm 0 \cdot 1^{\circ} \mathrm{C}$; time $=300 \mathrm{~min}$; solvent $=$ dioxene.

$$
\begin{aligned}
& \log \frac{R_{p}^{2}}{[Y][M]^{2}} \\
& \quad=\log \frac{2 f_{k} k_{d} k_{p}^{2}}{k_{t}}-0.8684 \frac{k_{p r t}}{k_{y} \times k_{p}} \times \frac{R_{p}}{[M]^{2}},
\end{aligned}
$$

where $Y$ and $M$ represent ylide and monomer respectively. A plot of the above equation vs $R_{p} /[M]^{2}$ gave a negative slope (figure 6) indicating primary radical termination due to ylide for the present system. The following equation, derived by $\mathrm{Deb}^{24}$ and further simplified by Ghosh and Mitra ${ }^{25}$ was used to examine the role of ylide as degradative chain transfer agent:

$$
\begin{aligned}
& \log \frac{R_{p}^{2}}{[Y][M]^{2}} \\
& \quad=\frac{\log 2 f_{k} k_{d} k_{p}^{2}}{k_{t}}-0.434 \frac{k_{p}^{2}}{k_{t}} \times \frac{k_{r t} Y}{k_{i l} k_{p}} \times C_{1} \frac{[Y]}{[M]},
\end{aligned}
$$

where $C_{1}$ is the ylide transfer constant. The plot of the above equation vs $[Y] /[M]$ also gave a negative slope (figure 7), thereby suggesting chain transfer reaction due to ylide.

The non-ideal kinetics in the arsonium ylide initiated polymerization of vinyl monomers like vinyl acetate $^{14} \mathrm{MMA}^{13,26}$ has been attributed to primary

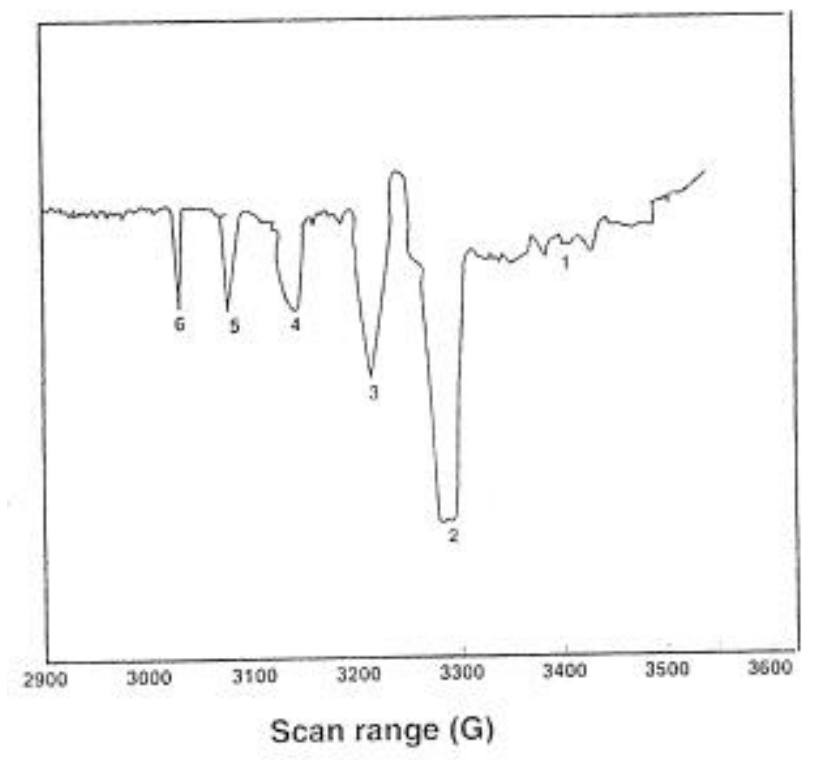

Figure 8. ESR spectrum of polymethyl methacrylate mixture. 
radical termination and degradative chain transfer reaction. Further the polymerization of few vinyl monomer initiated by $\mathrm{N}^{8,9,27}$ and $\mathrm{P}^{28}$ ylide also follows non-ideal kinetics due to primary radical termination and degradative chain transfer.

\section{Mechanism}

The effect of free radical inhibitors like hydroquinone, aniline and nitrobenzene on the polymerizaiton under the same reaction conditions (table 3) has also been studied to conform free radical mode of polymerization. Triphenylstibonium 1,2,3,4-tetraphenylcyclopentadienylide undergoes bond fission between the heteroatom and the phenyl group to yield phenyl radical $^{29}$ which initiates polymerization reaction. This is confirmed by ESR spectrum (the ESR spectrum was recorded on X-band EPR 109 Eline century series spectrometer at room temperature) of living system at $2 \mathrm{~h}$ which show six hyperfine lines due to the phenyl radical (figure 8).

\subsection{Generation of initiator radical}

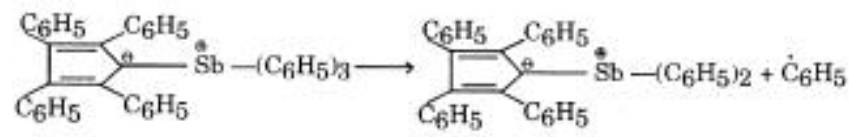

The initiation step is as follows:<smiles>CCOC(=O)C(C)(CCc1ccccc1)CC(=O)OCc1ccccc1</smiles>

\section{Conclusions}

On the basis of the above evidences it may be concluded that the polymerization of methyl methcrylate initiated by triphenyl stibonium 1,2,3,4-tetraphenycyclopentadienylide, follows non-ideal radical kinetics due to primary radical termination as well as degradative chain transfer reaction.

\section{Acknowledgement}

The authors are grateful to Dr K P Singh for encouragement.

\section{References}

1. Dutta A, Mohato P K and Dass N N 1991 Eur. Polym. J. 27465

2. Xia P, Cheng H and Yan D 1991 J. Appl. Polym. Sci. 45579

3. Casinos I 1994 Polym. Int. 33387

4. Ohtami H, Tanaka M and Tsuge S 1990 Bull. Chem. Soc. 463

5. Nakamura T, Soyama S and Bushfield W K 1998 Polymer 406

6. Seno M and Fukunoga H 1998 J. Polym. Sci. 36 2906

7. Srivastava A K and Saini S 1985 J. Macromol. Sci. Chem. 122

8. Srivastava A K, Saini S, Nigam S K and Rai J S P 1987 Eur. Polym. J. 23913

9. Saini S, Vasishtha R, Shukla $\mathrm{P}$ and Srivastava A K 1989 Macromolecules 221025

10. Saini S, Shukla A K, Kumar P and Srivastava A K 1987 Acta Polym. 384321

11. Vasishtha R and Srivastava A K 1989 Polym. J. 21 103

12. Kondo S, Kondo Y and Tsuda K L 1983 Polym. Sci. 21213

13. Srivastava A K and Daniel N 2000 J. Polym. Res. 7 161

14. Daniel $\mathrm{N}$ and Srivastava A K Eur. Polym. J. 37 2313

15. Daniel N and Srivastava A K 2002 Adv. Polym. Tech. 21108

16. Overberger R and Yamamoto N 1966 J Polym. Sci. 4 3101

17. Vogel A I 1956 A text book of practical organic chemistry (London: Longman)

18. Glidewell C and Lloyd D 1988 Synthesis 319

19. Taninaka T, Ogawa T and Minoure Y 1975 J. Polym. Sci., Polym. Chem. 13681

20. Vasishtha R and Srivastava A K 1990 Polymer 31 150

21. Saini S and Srivastava A K 1985 J. Macromol. Sci. Chem. 2243

22. Saini S, Shukla A K, Kumar P and Srivastava A K 1987 Polym. J. 4243

23. Deb P C and Meyerhoff G 1974 Eur. Polym. J. 10 709

24. Deb P C 1975 Eur. Polym. J. 1131

25. Ghosh P and Mitra P S 1977 J. Polym. Sci., Polym. Chem. 151743

26. Kaur M and Srivastava A K 1998 J. Photochem. Photobiol. 11967

27. Vasishtha R, Awashi S and Srivastava A K 1990 British Polym. J. 2253

28. Vasishtha R and Srivastava A K 1991 Polym. Eng. Sci. 318

29. Bovey F A and Klothoff I M 1948 Chem Rev. 42 491 